\title{
Relationship between Speech Perception and Level of Satisfaction of Hearing Aid Users
}

\author{
Erika Barioni Mantello ${ }^{1}$ Carla Dias da Silva ${ }^{1}$ Eduardo Tanaka Massuda ${ }^{1}$ Miguel Angelo Hyppolito ${ }^{1}$ \\ Ana Cláudia Mirândola Barbosa dos Reis ${ }^{1}$ \\ ${ }^{1}$ Department of Ophthalmology, Otorhinolaryngology and Head and \\ Neck Surgery, Ribeirão Preto Medical School, Universidade de \\ São Paulo, Ribeirão Preto, São Paulo, Brazil \\ Int Arch Otorhinolaryngol 2016;20:315-320.

\begin{abstract}
Address for correspondence Erika Barioni Mantello, Fga, PhD, Department of Ophthalmology, Otorhinolaryngology and Head and Neck Surgery, Ribeirão Preto Medical School,University of São Paulo, Av Bandeirantes 3600, Campus Ribeirão Preto, São Paulo 14049-900,
\end{abstract} \\ Brazil (e-mail: erikafga@yahoo.com.br).
}

\begin{abstract}
Keywords

- hearing perception

- patient satisfaction

- hearing loss

- hearing aids

- questionnaires

Introduction Hearing difficulties can be minimized by the use of hearing aids.

Objective The objective of this study is to assess the speech perception and satisfaction of hearing aids users before and after aid adaptation and to determine whether these measures are correlated.

Methods The study was conducted on 65 individuals, $54 \%$ females and $46 \%$ males aged 63 years on average, after the systematic use of hearing aids for at least three months. We characterized subjectś personal identification data, the degree, and configuration of hearing loss, as well as aspects related to adaptation. We then applied a satisfaction questionnaire and a speech perception test (words and sentences), with and without the use of the hearing aids.

Results Mean speech recognition with words and sentences was $69 \%$ and $79 \%$, respectively, with hearing aids use; whereas, without hearing aids use the figures were $43 \%$ and $53 \%$. Mean questionnaire score was 30.1 points. Regarding hearing loss characteristics, $78.5 \%$ of the subjects had a sensorineural loss, $20 \%$ a mixed loss, and $1.5 \%$ a conductive loss. Hearing loss of moderate degree was present in $60.5 \%$ of cases, loss of descending configuration in $47 \%$, and plain loss in $37.5 \%$. There was no correlation between individual satisfaction and the percentages of the speech perception tests applied.

Conclusion Word and sentence recognition was significantly better with the use of the hearing aids. The users showed a high degree of satisfaction. In the present study, there was no correlation observed between the levels of speech perception and levels of user satisfaction measured with the questionnaire.
\end{abstract}

\section{Introduction}

Hearing disability derives from a deficiency in hearing ability and the performance of an individual in communication. The severity of the disability depends on the nature and magnitude of hearing loss and, consequently, on the hearing difficulties experienced by the listener. ${ }^{2}$

received

September 24, 2015

accepted

November 6, 2015

published online

December 17, 2015
Hearing disability derives from a deficiency in hearing ability and the performance of an individual in communication. The severity of the disability depends on the nature and magnitude of hearing loss and, consequently, on the hearing difficulties experienced by the listener. ${ }^{2}$

Thus, one of the objectives of a hearing aid is to reduce or eliminate the limitations caused by hearing loss. ${ }^{1}$ Over the

Copyright $\odot 2016$ by Thieme Publicações License terms Ltda, Rio de Janeiro, Brazil

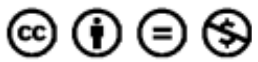


last few years, hearing aids (HA) have been used as a primary intervention option for users with hearing loss who cannot be treated clinically or surgically. ${ }^{1}$

Tests such as detection of hearing thresholds with the use of electronic devices and measures with a probe microphone are not always sufficient to assess and ensure the adaptation of HA in daily communication situations. Over the past decades, there has been increased interest in the development of verification and validation procedures to assess the benefits and user satisfaction outside the clinical environment, through self-assessment questionnaires. ${ }^{3}$

Although HAs minimize the impact of hearing loss in affected subjects, their use cannot restore normal hearing. They are meant to provide the largest possible amount of acoustic information, but they do not always contribute to improving speech intelligibility with a consequent effective communication. ${ }^{4}$ The benefit obtained by the use of these devices can be measured as positive, negative or neutral, depending on the effect the device has on each individuals performance. $^{5}$

For an efficient fitting of the HA, it is of primary importance to apply guidance and monitoring programs to their users, with active user participation whenever possible. Selfassessment questionnaires are important instruments that help speech therapists to monitor the users of these devices and provide information about the difficulties of HA use. ${ }^{6,7}$

One example is the self-assessment questionnaire called International Outcome Inventory for Hearing Aids (IOI-HA), ${ }^{8,9}$ whose goal is to document the user's progress, the limitations of core activities, the restriction of participation, and the impact of the hearing problem to others, and to the quality of life. ${ }^{8-11}$

The application of the IOI-HA questionnaire allows the documentation of success and the monitoring of the progress of HA use in userś daily routine, in addition to the benefit and the degree of user satisfaction. Also, it can assess the benefit in of listening in unfavorable situations such as noisy environments and helps to reduce the impact of the individuals hearing loss over others. ${ }^{12}$

As the population ages, the number of candidates for HA fitting will significantly increase over the next years. ${ }^{13}$ It is essential to develop diagnostic and rehabilitation programs for the elderly with hearing loss to foster their participation in social relations. ${ }^{14}$

Studies have demonstrated the need to assess speech perception and user satisfaction after HA fitting, with several investigations contributing to the adaptation and validation of speech perception tests to different listening situations and to the improvement of satisfaction questionnaires.

The primary objective of the present study was to assess the speech perception and level of satisfaction of HA users before and after fitting for the device and to determine whether these measurements are correlated. Specific objectives were to determine the association between sex and degree of hearing loss and each question of the IOI-HA, as well as to relate patient age and time of HA use with each IOI-HA question.

\section{Methods}

This study was a cross-sectional, prospective study of a descriptive nature, with approval from the institutiońs Research Ethics Committee (protocol nº. 7629/2008). The selected subjects gave written informed consent to participate.

Inclusion criteria were: age of at least 18 years, use of HA with at least three months of adaptation, and HA purchased through the program of Attention to Hearing Health of the institution, according to ordinances SAS-MS $\mathrm{n}^{\circ} .587$ and 589 of October 7 and 8,2004, in effect at the time of the study. ${ }^{15,16}$

Exclusion criteria were patients with auditory neuropathy spectrum, neurological, psychological, and cognitive impairments, or any problems that could affect the accuracy of the answers in the procedure used after evaluation by a multidisciplinary team.

The study was conducted during a monitoring visit in the speech therapy sector of the institution and the data obtained included

identification information, data related to the degree and configuration of hearing loss, and aspects related to HA fitting.

We then applied a questionnaire as a face-to-face directed interview with the patient. The speech therapist would orally present the questions in the questionnaires, noting the answer, avoiding irrelevant comments to preserve the accuracy of the responses.

We used the IOI-HA questionnaire ${ }^{12}$ because it allows the documentation of the performance of the HA in use, in terms of daily use, benefit, limitation of basic activities, satisfaction, restriction of participation, impact on other persons and quality of life.

The IOI-HA contains a total of seven questions, with five optional responses to each one and with a score ranging from one to five, from the worst answer to the best. The maximum score (the sum of all items) is 35 points. Thus, a higher score indicates a positive assessment of the performance of the HA user and a lower score indicates a negative assessment. ${ }^{11}$

We analyzed the survey responses considering the total score and the scores of the two factors. ${ }^{17,18}$ The factor number one reflects the interaction of the patients with their HA (questions 1, 2, 4, and 7; with a score that varies between 4 to 20 ) and the factor number two evaluated patient interaction with others in their environment (questions 3, 5, and 6; score ranging from 3 to 15 ).

Then, we presented the the recognition list disyllables and Lacerda phrases ${ }^{19}$ through the speakerphone, with and without $\mathrm{HA}$, in an acoustically treated room at a distance of $50 \mathrm{~cm}$ from the individual's ear, the $0^{\circ}$ azimuth, and an intensity of $65 \mathrm{~dB}$ SPL (measured with a decibel meter (make and model).

\section{Statistical Analysis}

We performed an exploratory analysis of the data to summarize the information. We used the Spearman correlation coefficient to correlate the differences in words and sentences with the total result of the IOI-HA questionnaire. We used mixed-effect (random and fixed effects) linear regression 
Table 1 Mean values, confidence interval, and standard deviation of the continuous variables

\begin{tabular}{|l|l|l|l|l|l|l|l|}
\hline Variable & \multirow{2}{*}{ Mean } & \multicolumn{2}{l|}{$\mathbf{9 5 \% \text { CI }}$} & SD & Minimum & Median & Maximum \\
\cline { 3 - 6 } & & LL & UL & & & & \\
\hline Age & 62.18 & 57.02 & 67.35 & 20.85 & 12.00 & 70.00 & 89.00 \\
\hline Time of hearing loss (years) & 11.08 & 9.43 & 12.72 & 6.64 & 5.00 & 10.00 & 20.00 \\
\hline Time of HA use (months) & 46.60 & 31.94 & 61.26 & 59.15 & 5.00 & 24.00 & 396.00 \\
\hline Word recognition with the HA & 69.38 & 63.44 & 75.33 & 23.99 & 0.00 & 72.00 & 100.00 \\
\hline Word recognition without the HA & 42.89 & 34.77 & 51.01 & 32.76 & 0.00 & 52.00 & 96.00 \\
\hline Sentence recognition with the HA & 79.38 & 72.94 & 85.83 & 26.00 & 0.00 & 92.00 & 100.00 \\
\hline Sentence recognition without the HA & 52.92 & 43.79 & 62.06 & 36.87 & 0.00 & 60.00 & 100.00 \\
\hline Total IOI-HA score & 30.06 & 29.12 & 31.01 & 3.81 & 21.00 & 30.00 & 35.00 \\
\hline
\end{tabular}

Abbreviations: $\mathrm{Cl}$, confidence interval; $\mathrm{HA}$, hearing aid; LL, lower limit; SD, standard deviation; UL, upper limit.

models to compare the recognition of words and sentences between patients with and without HA. Mixed-effect linear models are helpful in analyzing data involving grouped responses (repeated measures for the same individual) when the assumption of independence between observations in the same group is inadequate. ${ }^{20}$ This model is based on the assumption that the residue obtained from the difference between the values predicted by the model and the observed values has a normal distribution, with 0 mean and constant variance.

To achieve the specific objectives, we used crossedtabulation of the variables, the Fisher exact test (sex and degree of loss determined by the questions of the IOI-HA) and the Spearman correlation coefficient to compare between age and time of HA use and the questions of the IOI-HA. We considered $P$ values of less than 0.05 and correlation values higher than 0.60 to be significant. We performed all analyses were with the aid of the SAS software version $9.3,{ }^{21}$ and plotted the graphs with the aid of the $\mathrm{R}$ software. ${ }^{21-23}$

\section{Results}

The study was conducted on 65 adult and elderly users, $54 \%$ of them women and $46 \%$ men, followed-up in the Hearing Health Program of the institution of origin. Mean patient age was 63 years (range: $18-89$ years).
- Table 1 presents the mean values, confidence interval, and standard deviation of the continuous variables.

Eighty percent of the subjects had a hearing loss of the sensorineural type, $20 \%$ of the mixed type, and $1.5 \%$ of the conductive type. Hearing loss of moderate degree prevailed among $60.7 \%$ of cases, followed by loss of the severe degree in $23 \%$, profound loss in $14.6 \%$, and mild loss in $1.54 \%$. Configuration was descending in $47.3 \%$ of cases, followed by the plain configuration in 34.9 , ascending configuration in $3.0 \%$, and other configurations in $14.7 \%$. Sixty percent of the 65 participants had hearing loss of a progressive nature and $40 \%$ had stable hearing loss.

A HA of the retro auricular type was fitted to $96 \%$ of the users, $94 \%$ of whom used a bilateral HA.

Mean speech recognition was $69 \%$ for words and $79 \%$ for sentences with the use of the HA, and $43 \%$ and $53 \%$, respectively, without the HA.

- Table 2 lists the significant p-values $(p<0001)$ obtained when we compared word and sentence recognition between the presence and absence of the HA.

-Figs. 1 and $\mathbf{2}$ respectively illustrate the distribution of word and sentence recognition with and without the use of the HA.

The mean score obtained with the IOI-HA questionnaire was 30.1 points (range: $21-35$ points). The comparison of the average total score of the IOI-HA with the degree of hearing loss yielded mean values of 31.4 points for the severe degree,

Table 2 Estimated difference and significant p-values for the comparison of word and sentence recognition in the speech recognition test with and without the $\mathrm{HA}$

\begin{tabular}{|c|c|c|c|c|}
\hline \multirow[t]{2}{*}{ Effect } & \multirow[t]{2}{*}{ Estimated difference } & \multirow[t]{2}{*}{$P$ value } & \multicolumn{2}{|l|}{$95 \% \mathrm{Cl}$} \\
\hline & & & $\mathrm{LL}$ & UL \\
\hline Words* & 26.492 & $<0.001$ & 16.526 & 36.458 \\
\hline Sentences ${ }^{* *}$ & 26.461 & $<0.001$ & 15.387 & 37.535 \\
\hline
\end{tabular}

Abbreviations: $\mathrm{Cl}$, confidence interval; LL, lower limit; UL, upper limit; SD, standard deviation.

* word recognition in the presence and absence of the HA

${ }^{* *}$ sentence recognition in the presence and absence of the HA. 


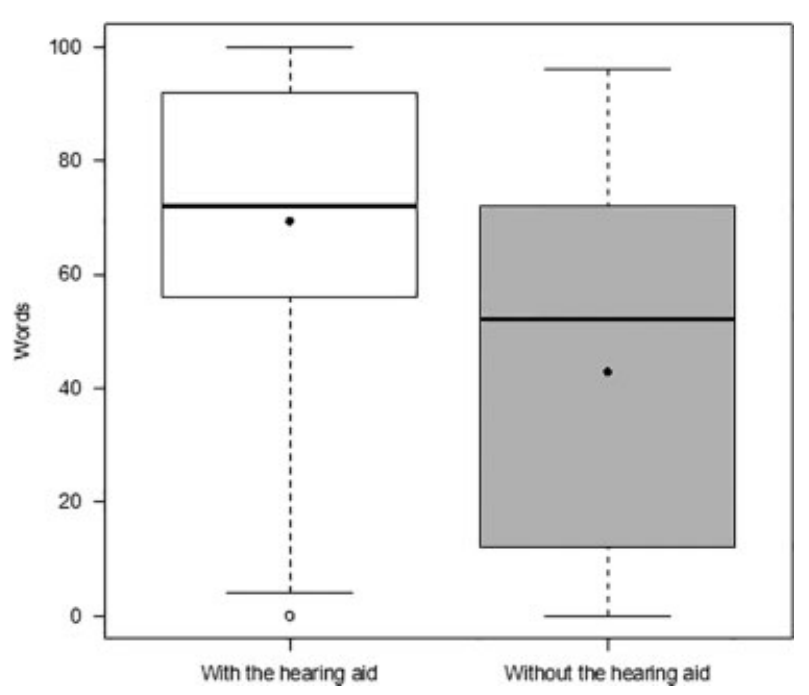

Fig. 1 Boxplot of the distribution of word recognition in the presence and absence of the hearing aid.

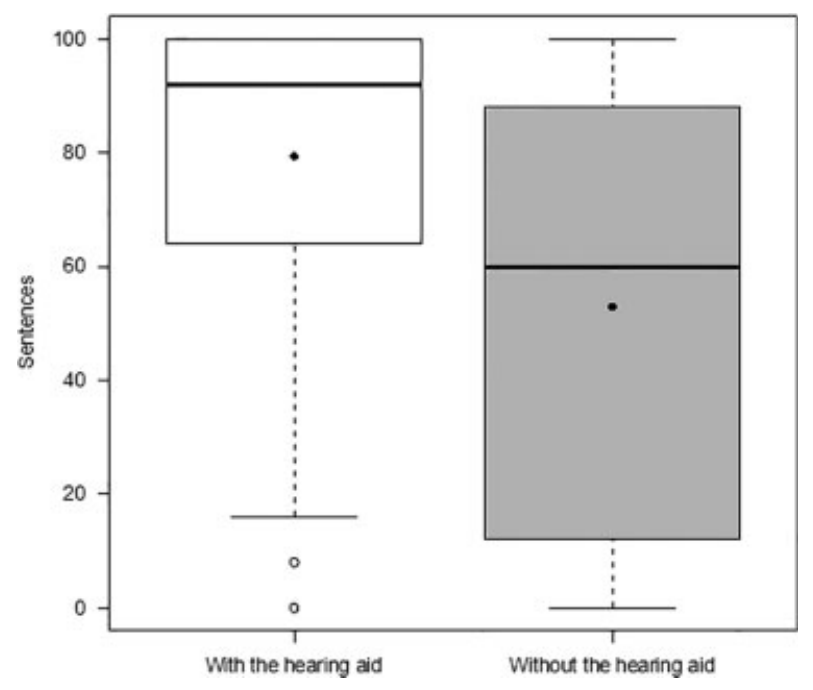

Fig. 2 Boxplot of the distribution of sentence recognition in the presence and absence of the hearing aid.

31 points for the mild degree, 29.6 points for the moderate degree, and 29.2 for the profound degree.

We considered the correlation coefficient regarding the difference in word recognition (0.21) and sentence recognition $(0.20)$ before and after the use of the HA compared with the results of the IOI-HA weak.

There was a moderate correlation between the difference in word recognition and the difference in sentence recognition (0.69).

We found no significant results regarding the association of patient gender with each question of the IOI-HA.

We detected no correlation between time of HA use and each issue of the IOI-HA, or between patient age and each issue of the IOI-HA.

Similarly, there was no significant association detected between the degree of hearing loss in the right and left ears and each question of the IOI-HA.

\section{Discussion}

The motivation for this study was based on the need to analyze the correlation between speech perception test, commonly used in clinical practice, and the self-perception among subjects, specifically in relation to satisfaction of adults and elderly HA users. Within the process of speech therapy intervention, this is one of the actions that has an interactive and communicative component in the encounter between the specialist and the user, which can either facilitate or hamper the achievement of their objectives.

In the present study, there was a high participation of the elderly population (mean age: 63 years), in agreement with other studies. ${ }^{24,25}$ With increased life expectancy, the elderly population, which is affected by presbyacusis among other changes, has grown. ${ }^{26}$ Studies have demonstrated that hearing loss starts at $\sim 30$ years of age, progressively increasing over the years. ${ }^{26-28}$

We balanced the present sample in terms of sex (54\% women and $46 \%$ men), reflecting a current trend in health services, as opposed to reports published several years ago, ${ }^{29}$ which showed a prevalence of females in general, as was the case in hearing health services. We also observed this gender equilibrium in another study, in which $48.54 \%$ of the elderly subjects investigated were males and $51.46 \%$ were females. ${ }^{30}$

Although most of the present users were elderly, their mean time of hearing loss was 11 years, with an interval of $\sim 7$ years before the acquisition of the HA. We conducted this study on subjects covered by a Hearing Health Program accredited by the Unified Health System (SUS), which involved high demand and a waiting line of over two years before the definitive fitting of the HA, in agreement with other studies. ${ }^{25,29}$

The present study revealed a significant gap between diagnosis and HA fitting. The literature attributes this delay to the reluctance of adult users in accepting their hearing loss while attributing their hearing difficulties to an inappropriate environment or to communication by third parties.

Most users had a hearing loss of the sensorineural type of moderate degree, with a descending configuration and of a progressive nature, compatible with the auditory characteristics detected in the population of elderly individuals with presbyacusis. The reduced auditory sensitivity resulting from aging known as presbyacusis, which is characterized by bilateral symmetric sensorineural hearing loss of descending configuration..$^{31,32}$ We should, however, emphasize an important reduction of speech intelligibility, which may be incompatible with audiometric thresholds in some users, a fact that can also be explained by a decline in auditory processing. $^{31-33}$

Almost the entire sample evaluated consisted of users of bilateral HA, as also reported in many literature studies. ${ }^{25-29}$ The advantages of bilateral hearing are well known in the documentation, allowing better localization of the sound source, better speech recognition, and figure-ground relationship, factors that are crucial for individuals with hearing loss. $^{34}$ 
In the present study, there was a predominance of fitting of an HA of the retroauricular type (96\%), in agreement with other literature reports on this topic. ${ }^{29,35}$ The greater indication of retroauricular devices is explained by the fact that they can adapt to all degrees of hearing loss, from mild to profound. Moreover, they offer greater amplification power and increased handling ease. ${ }^{36}$ Thus, they were more appropriate for the sample studied, as it mainly consisted of elderly subjects with little manual dexterity and with a higher probability of worsening hearing thresholds, especially at high frequencies.

In the process of HA fitting, the intention is to provide better audibility of acoustic signals and better speech intelligibility to the patient with hearing deficiency to reduce his hearing disability. ${ }^{37}$ Thus, the benefit provided by the use of amplification is the difference in individual performance between the presence and the absence of the hearing device.

The improvement of communication in daily life and the reduction of hearing disability and handicap of HA users are benefits inherent to the use of the electronic devices. ${ }^{18}$ This statement agrees with the results of the present study, since the patients had a mean $26 \%$ difference in the recognition of words and sentences with and without the use of HA and a high score in the IOI-HA questionnaire.

It was also observed in this study a higher percentage of correct responses in the recognition of sentences when comparing to words. Freitas et $\mathrm{al}^{38}$ stated that the use of sentences is more appropriate to assess speech recognition in noise. Sentences are more similar to situations of everyday communication, moving closer to the spectral characteristics and contexts of everyday speech, controlling the duration and semantic content of it.

The results obtained in the present study with the use of the IOI-HA demonstrated that satisfaction appears to be a more faithful measure, since it includes a multitude of factors, has a dynamic character, depends on the perception and attitudes of the user, and is not solely related to the performance of the hearing device. The self-assessment questionnaires determine the psychosocial impact of hearing loss or the benefit of sound amplification and evaluate in a standardized manner the results of the speech therapy procedures directed at patient subjectivity, thus, guiding the fitting process. $^{39}$

Previous studies have demonstrated that the use of HA is essential to maintain the physical and mental health of the elderly, since it allows them to participate more in their community and in family life. ${ }^{40}$

Despite the significant difference in the rate of recognition of both words and sentences between the use or not of the HA (-Table 2), there was a weak correlation between speech perception before and after the utilization of the HA compared with the results of the IOI-HA.

Similarly, other authors did not find a difference in satisfaction with the HA after hearing rehabilitation (training in speech perception). ${ }^{41,42}$ They explain that the concept of happiness is more frequently employed to justify or criticize the fitting methods, the qualification of the speech therapist, and the practice of the industries who distribute the HA. ${ }^{43}$
This, however, does not necessarily represent device performance, since a patient may have a significant degree of benefit measured by a test with and without HA, but may be dissatisfied with sound amplification. ${ }^{44-47}$

These results suggest that further research is needed in this sense, seeking instruments and forms of application that can correlate the level of user satisfaction with the clinical audiological assessment performed by the professionals who work with HA fitting.

For such, it is important to highlight the importance of audiological monitoring of patients covered by the hearing health services of the Unified Health System (SUS), which involves extensive work that ranges from monitoring hearing loss to fine adjustments of the HA to maximize its benefits, as well as research on how the device improves the patients quality of life. ${ }^{48}$

\section{Conclusion}

In our study, we observed a better performance in terms of word and sentence recognition with the use of the HA, with a significant difference between the conditions of device presence or lack thereof, with the percentage of speech perception being higher when the patient tested with sentences.

There was no correlation between the results of the speech perception test and the level of HA user satisfaction, although the results of IOI-HA revealed that the users were satisfied with their devices.

\section{References}

1 Bento RF, Neto RB, Castilho AM, et al. Resultados auditivos com o implante coclear multicanal em pacientes submetidos à cirurgia no Hospital das Clínicas da Faculdade de Medicina da Universidade de São Paulo. Rev Bras Otorrinolaringol (Engl Ed) 2004; 70:632-637

2 Frederigue NB, Bevilacqua MC. Otimização da percepção da fala em deficientes auditivos usuários do sistema de implante coclear multicanal. Rev Bras Otorrinolaringol (Engl Ed) 2003; 69:227-233

3 Almeida K. Avaliação dos resultados da intervenção. In: Almeida K, Iorio MCM. Próteses auditivas: fundamentos teóricos e aplicações clínicas. São Paulo: Lovise; 2003:335-352

4 Russo ICP. A intervenção fonoaudiológica na terceira idade. Rio de Janeiro: Revinter; 2004:67-78

5 Fleck MPA, Chachamovich E, Trentini CM. [WHOQOL-OLD Project: method and focus group results in Brazil]. Rev Saude Publica 2003; 37(6):793-799

6 Mondelli MFCG, Souza PJS. Qualidade de vida em idosos antes e após a adaptação do AASI. Braz J Otorhinolaryngol 2012;78(3): 49-56

7 Rosa MRD, Dantes GE, Ribas A. Programa de Orientação a Usuários de Prótese Auditiva e Questionários de Auto-avaliação: Importantes Instrumentos para uma Adaptação Auditiva Efetiva. Int Arch Otorhinolaryngol 2006;3:220-227

8 Cox RM, Alexander GC. The international outcome inventory for hearing aids (IOI-HA): psychometric properties of the English version. Int J Audiol 2002;41(1):30-35

9 Cox RM. Assessment of subjective outcome of hearing aid fitting: getting the client's point of view. Int J Audiol 2003;42(1, Suppl 1): S90-S96 
10 Cox RM, Alexander GC, Beyer CM. Norms for the international outcome inventory for hearing aids. J Am Acad Audiol 2003;14(8): 403-413

11 Cox R, Hyde M, Gatehouse S, et al. Optimal outcome measures, research priorities, and international cooperation. Ear Hear 2000; 21(4, Suppl)106S-115S

12 Teixeira CF, Augusto LGS, Caldas Neto SS. Prótese auditiva: satisfação do usuário com sua prótese e com seu meio ambiente. Rev CEFAC 2008;10(2):245-253

13 Lessa AH, Costa MJ, Becker KT, Vaucher AVA. Satisfação de usuários de próteses auditivas, com perda auditiva de graus severo e profundo. Arq Int Otorrinolaringol 2010;14(3):338-345

14 Veras RP, Mattos LC. Audiology and aging: literature review and current horizons. Braz J Otorhinolaryngol 2007;73(1): 122-128

15 Brasil. Ministério da Saúde. Portaria MS/SAS n ${ }^{\circ}$ 587, de 7 de outubro de 2004. Available at: http://www.saude.mg.gov.br/images/documentos/Portaria_587.pdf. Accessed on February 11, 2014

16 Brasil. Ministério da Saúde. Portaria MS/SAS nº 589 de 8 de outubro de 2004. Available at: http://www.saude.mg.gov.br/images/documentos/Portaria_589.pdf. Accessed February 11, 2014

17 Cox RM, Alexander GC, Gray GA. Personality, hearing problems, and amplification characteristics: contributions to self-report hearing aid outcomes. Ear Hear 2007;28(2):141-162

18 Prates LPCS, Iório MCM. Aclimatização: estudo do reconhecimento de fala em usuários de próteses auditivas. Pró Fono R Atual Cient 2006;18(3):259-266

19 Lacerda AP. Audiologia clínica. Rio de Janeiro: Guanabara Koogan; 1976:199

20 Schall R. Estimation in generalized linear models with random Effects. Biometrika 1991;78(4):719-727

21 SAS Institute Inc. SAS/STAT® User's Guide, Version 9. Cary, NC: SAS Institute Inc.; 1999

22 Pagano M, Gauvreau K. Princípios de Bioestatística. São Paulo: Thomson; 2004:320

23 R Development Core Team. (2011). R: A language and environment for statistical computing. R Foundation for Statistical Computing, Vienna, Austria. ISBN 3-900051-07-0

24 Farias RB, Russo ICP. Saúde auditiva: estudo do grau de satisfação de usuários de aparelho de amplificação sonora individual. Rev Soc Bras Fonoaudiol 2010;15(1):26-31

25 Moda I, Mantello EB, Reis ACMB, et al. Avaliação da satisfação do usuário de aparelho de amplificação sonora. Rev CEFAC 2013; 15(4):778-785

26 Megighian D, Savastano M, Salvador L, Frigo A, Bolzan M. Audiometric and epidemiological analysis of elderly in the Veneto region. Gerontology 2000;46(4):199-204

27 Bance M. Hearing and aging. CMAJ 2007;176(7):925-927

28 Campos CAH, Russo ICP, Almeida KCP. Indicação, seleção e adaptação de próteses auditivas. In: Almeida K, Iorio MCM. Próteses auditivas: fundamentos teóricos e aplicações clínicas. São Paulo: Lovise; 2003:35-53

29 Antoniossi NM, Reis ACMB. Análise do tipo, adaptação e uso de HAI adquiridos pelo programa de Saúde Auditiva do HCFMRP/USP [Dissertation]. Ribeirão Preto (SP): Faculdade de Medicina de Ribeirão Preto da Universidade de São Paulo, Phonoaudiology Department; 2007
30 Gomes MM. Programa de saúde auditiva: perfil dos usuários e avaliação dos resultados obtidos na intervenção fonoaudiológica [Dissertation]. Campinas (SP): Faculdade de Ciências Médicas de Campinas, Universidade Estadual de Campinas; 2014

31 Russo ICP. Distúrbios da Audição: A Presbiacusia. In: Russo ICP. Intervenção Fonoaudiológica na Terceira Idade. Rio de Janeiro: Revinter; 2004:51-82

32 Aiello CP, Lima II, Ferrari DV. Validity and reliability of the hearing handicap inventory for adults. Braz J Otorhinolaryngol 2011; 77(4):432-438

33 Sousa MGC, Russo ICP. Audição e percepção da perda auditiva em idosos. Rev Soc Bras Fonoaudiol 2009;14(2):241-246

34 Magni C, Freiberger F, Tonn K. Avaliação do grau de satisfação entre os usuários de amplificação de tecnologia analógica e digital. Rev Bras Otorrinolaringol (Engl Ed) 2005;71(5):650-657

35 Batista ACM, Sampaio FM. Nível de satisfação dos idosos usuários de próteses auditivas doadas pela APAC-NAMI UNIFOR. Rev Bras Prom Saúde 2005;18(1):7-10

36 Assayag FHM, Russo ICP. Avaliação subjetiva do benefício e dos efeitos proporcionados pelo uso de amplificação sonora em indivíduos idosos. Rev Dist Comun 2006;18(3):383-390

37 Almeida K. Avaliação objetiva e subjetiva dos benefícios das próteses auditivas em adultos [Thesis]. São Paulo (SP): Universidade Federal de São Paulo, Escola Paulista de Medicina; 1998

38 Freitas CD, Lopes LFD, Costa MJ. Confiabilidade dos limiares de reconhecimento de sentenças no silêncio e no ruído. Rev Bras Otorrinolaringol (Engl Ed) 2005;71(5):624-630

39 Macedo LS, Pupo AC, Balieiro CR. Aplicabilidade dos questionários de auto-avaliação em adultos e idosos com deficiência auditiva. Rev Dist Comun 2006;18(1):19-25

40 Silva BSR, Sousa GB, Russo ICP, Silva JAPR. Characterization of the complaints, kind of hearing loss and treatment for elderly people seen at a private clinic in Belem - PA. Arq Int Otorhinolaryngol 2007;11(4):387-395

41 Saunders GH, Lewis MS, Forsline A. Expectations, prefitting counseling, and hearing aid outcome. J Am Acad Audiol 2009; 20(5):320-334

42 Kramer SE, Allessie GH, Dondorp AW, Zekveld AA, Kapteyn TS. A home education program for older adults with hearing impairment and their significant others: a randomized trial evaluating short- and long-term effects. Int J Audiol 2005;44(5):255-264

43 Ross M, Levitt H. Consumer satisfaction is not enough: Hearing aids still about hearing. Semin Hear 1997;18(1):7-10

44 Araújo TM, Morettin M, Torres KCC, et al. Auditory Rehabilitation and Life Quality of Individual Hearing Aids Users: Systematic Review. Rev Dist Comun 2010;22(1):25-36

45 Cox RM, Alexander GC. Measuring satisfaction with amplification in daily life: the SADL scale. Ear Hear 1999;20(4):306-320

46 Hosford-Dunn $\mathrm{H}$, Halpern J. Clinical application of the satisfaction with amplification in daily life scale in private practice I: statistical, content, and factorial validity. J Am Acad Audiol 2000;11(10): 523-539

47 Veiga LR, Merlo ARC, Mengue SS. Satisfação com a prótese auditiva na vida diária em usuários do Sistema de Saúde do Exército. Rev Bras Otorrinolaringol (Engl Ed) 2005;71(1):67-73

48 Oliveira JRM, Lopes ES, Alves AF. Percepção de fala dos deficientes auditivos usando aparelho de amplificação com algoritmo de redução de ruído. Braz J Otorhinolaryngol 2010;76(1):14-17 